\title{
Foreword on the CIP-2005
}

The 15th International Colloquium on Plasma processes (CIP) was held at Autrans (near Grenoble in France) from June 6th to June 9th, 2005 with 150 participants, half of them from France and the others half from Germany, Japan, USA, China, etc.

The choice of Autrans was for the quality of the place in the Vercors mountains in Alps, near Grenoble and near the high-technical centers of plasma applications in micro and nanotechnology.

CIP is organized every two years by the French Vacuum Society (SFV).

Prior to the conference, 3 half days was for intensive courses (june 5th to june 6th) given by french specialists: Antoine Rousseau (Non thermal plasma physics), André Ricard (Optical diagnostics of plasma reactors), Alain Billard (Magnetron sputtering: from mechanical to functional applications), Agnès Granier (Deposition of thin films by PECVD), Fabienne Poncin-Epaillard (Plasma treatment of polymeric surfaces and applications to biomaterials engineering) and Christophe Cardinaud (Plasma etching for microelectronics and microtechnology).

The courses are published by SFV (sfv@vide.org).

The CIP conference was organized with Invited papers, oral and poster presentations in two parallel sessions.

The paper abstracts are in a booklet published by SFV.

The Invited papers were as follows (in the order of presentation during the conference):

- C. Lee (LAM-USA): New challenges in plasma etching for microelectronics.

- A. Hollander (Postdam, DE): Surface chemistry for biological and medical diagnostics.

- M. Chaker (Varennes, Quebec/CA): Pulsed laser deposition of advanced materials for device fabrication.

- E. Van Der Drift (Delft-NL): Tailoring plasmas to nanophotonic applications.

- K. Hassouni (Villetaneuse-FR): Reactivity of n-hexane soot particles in non-thermal atmospheric pressure discharges.

- P. Choquet (Arcelor-Liège-BE): Industrial establishment of new plasma vacuum solutions for large flexible strips: potentialities of steel into this new market.

- A. Gun Erlat (General Electric-NY-USA): PECVD ultrahigh barrier coatings for flexible optoelectronics.

- G. Cartry (Nantes-FR): Etching of low-k materials in inductively coupled fluorocarbon plasmas.

- J.M. Martin-Martinez (Alicante SP): Strategies to improve the adhesion of rubbers and polymers to adhesives by means of plasma surface modification. 
- J. Musil (Plzen-CZ): Nanocomposite coatings with enhanced hardness prepared by magnetron sputtering.

- M. Shiratani (Fukuoka-JP): Anisotropic deposition of Cu using plasma CVD for fabrication of nanoscale interconnects.

- P. Brault (Orléans-FR): Fuel cell synthesis by low pressure plasmas.

- W. Möller (Dresden-DE): Plasma immersion ion implantation: process, promises and prospects.

- T. Gans (Bochum-DE): Phase resolved optical emission spectroscopy of RF excited plasmas.

- M. Lieberman (Berkeley-USA): Physics of high frequency/multiple frequency capacitive discharges.

During the CIP 05, an exhibition of plasma equipments was organized with 13 participants.

At the end of the CIP 05, two prizes were attributed to Ph.D. students, the first one for the oral presentation to Cristina Canal (Barcelona-SP) and the second for the poster to Xavier Hubert (École Polytechnique/Palaiseau-F).

To conclude the CIP-2005 was a full success, due to the quality of talks and exchanges between participants, enhanced by the accommodation in the same residential center.

A. Ricard (Université Paul Sabatier, Toulouse, France)

G. Legeay (CTTM, Technopole Université, Le Mans, France) 